\title{
Flexible pensions for politicians
}

\section{Journal Article}

\section{Author(s):}

Gersbach, Hans; Mueller, Markus

Publication date:

2010-10

\section{Permanent link:}

https://doi.org/10.3929/ethz-b-000157687

\section{Rights / license:}

In Copyright - Non-Commercial Use Permitted

Originally published in:

Public Choice 145(1-2), https://doi.org/10.1007/s11127-009-9556-2 


\title{
Flexible pensions for politicians
}

\author{
Hans Gersbach • Markus Müller
}

Received: 18 December 2007 / Accepted: 17 October 2009 / Published online: 19 December 2009

(C) Springer Science+Business Media, LLC 2009

\begin{abstract}
It may be difficult to motivate politicians in their last term. To solve this problem, we suggest a triple mechanism involving political information markets, flexible pensions, and democratic elections. An information market is used to predict the potential reelection chances of the politician. Pensions depend on the price in the information market and thereby motivate the politician to act in a socially optimal manner. We show that, on balance, the triple mechanism increases social welfare. Finally, we suggest several ways to avoid the manipulation of information markets and we discuss possible pitfalls of flexible pensions.
\end{abstract}

Keywords Elections · Flexible pensions · Democracy · Information markets · Triple mechanism

JEL Classification D72 - D82

\section{Introduction}

In this paper we examine the last-period problem in connection with politicians, i.e., the problem of motivating an officeholder to work hard for the benefit of the public if he knows that it is his final term in office. Such incumbents may be tempted to shy away from working hard on socially desirable public projects.

We suggest a new mechanism for dealing with the problem of a lack of disciplining devices during this last term in office. The idea is to combine information markets and the politician's pension scheme. Our proposal can be outlined as follows: Suppose an officeholder learns that he would not like to run for reelection. This information is private. The politician has to decide how much effort he is still willing to expend on current policy projects. The effort choice is not verifiable. The public does not know whether or not the

H. Gersbach $(\bowtie) \cdot$ M. Müller

CER-ETH - Center of Economic Research at ETH Zurich and CEPR, 8092 Zurich, Switzerland

e-mail: hgersbach@ethz.ch

M. Müller

e-mail: markus.mueller@mip.mtec.ethz.ch 
politician wants to run again, so it organizes an information market predicting the chances of the incumbent being reelected. A high price on the information market indicates a high probability that the incumbent will be reelected. ${ }^{1}$ At some point in time, the incumbent announces whether he will seek a further term or not. In the former case, the information market is concluded when the next election has taken place. In the latter case, the information market is neutralized, i.e., the investors simply get their money back. The last price realized, however, is used in this case to determine the pension of the retiring incumbent. A higher price, and thus higher assessment of the incumbent's reelection chances, yields a higher pension.

Such a scheme involves two effects. On the one hand, the politician can increase his pension by increasing his efforts. On the other, flexible pensions decrease the marginal value of getting reelected as the gap between remuneration in office and the pension decreases with higher effort. The purpose of the paper is first to illustrate the idea in a simple political agency model and second to show that a carefully designed combination of political information markets and flexible pensions can-on balance-improve welfare.

The paper is organized as follows: In the next section we discuss the related literature. We introduce the basic model in Section 3. The results with fixed pensions are analyzed in Section 4. In Section 5 we introduce flexible pensions. Section 6 contains our main results. In Section 7 we discuss some issues concerning the practical implementation of flexible pensions for politicians. Section 8 concludes. The Appendix contains the proofs.

\section{Related literature}

Our paper is related to the literature about pensions for politicians and about the incentive problem in an incumbent's last term. ${ }^{2}$ The problem that the reelection mechanism can no longer motivate the incumbent when he knows that the term in question is his final one is described, e.g., in Barro (1973) and Carey (1994). ${ }^{3}$ Barro (1973) suggests solving the lastperiod problem in the following way: Political parties might provide a control mechanism for ex-officeholders based on their performance during their last term in office by appointing them to special positions in the party, such as honorary chairman. ${ }^{4}$ Another solution to the last-period problem has been suggested by Becker and Stigler (1974). They suggest that officeholders should be threatened with the loss of their pension in the case of malfeasance during their last term. Our solution to the last-term problem is to introduce an information market and design a flexible pension scheme depending on the resulting market price. ${ }^{5}$

\footnotetext{
${ }^{1}$ Alternatively, one might use an information market that predicts the percentage rate of votes the incumbent's party will receive, or even directly the shares of votes the incumbent party will be given. Such variations would not change the basic idea behind our proposal.

${ }^{2}$ The fact that the incumbent may not exert high effort during his last term is one form of political shirking which is defined as a legislator not acting in the interest of the public. A review of the literature on political shirking can be found e.g., in Bender and Lott (1996).

${ }^{3}$ Note that there may also be positive last-term effects as the probability that the incumbent undertakes longterm efficient policies that are unpopular in the short term may be higher when the politician knows that he is in his last term. The question of whether the overall effects of last terms are positive or negative is controversial in the literature (see for example Smart and Sturm 2004).

${ }^{4}$ We note that officeholders performing well may have better career opportunities after they leave office than worse performing ones, which alleviates the last-term problem.

${ }^{5}$ In this paper we concentrate on the case of politicians voluntarily retiring from their political career or losing in the reelection decision. We neglect the case where politicians have to leave office due to term limits. We will discuss how the last-term problem might be solved in the case of term limits in Sect. 8 .
} 
Another paper proposing a solution to the last-term problem in politics is Alesina and Spear (1988). In an overlapping generations model, they analyze a scenario where politicians have to choose a platform in a one-dimensional policy space. Without a reward, an incumbent will select his most preferred policy in his last term, which may deviate from one that is socially optimal. They suggest a solution where the current incumbent receives a transfer from his own party's next candidate for office if he does not choose his own bliss point, but a policy which increases this candidate's election chances. There are four differences between Alesina and Spear (1988) and the solution developed in our paper. First, the Alesina and Spear approach is based on the belief that a promise to reward incumbents for good performance today will be honored by the same reward scheme in the future. In our case, the reward for good performance is solely determined by the performance of the incumbent and does not depend on what will happen in the future. Second, the Alesina and Spear approach exhibits multiplicity of equilibria. In one equilibrium, the last period problem is not solved. We have a unique equilibrium. Third, we introduce an information market, which produces a verifiable outcome of the efforts of the politician. Such a mechanism is missing in Alesina and Spear. Fourth, our approach requires implementation through public pension laws, while the Alesina and Spear solution can work through conventions.

Our proposal for flexible pensions is related to the proposal to combine contracts and democratic elections introduced by Gersbach (2003, 2004), and extended by Gersbach and Liessem (2008). These papers show how the dual mechanism-incentive elements and elections - can improve political outcomes. All these papers rely on verifiable data by which contracts can be conditioned. In this paper, we analyze the case where the results from current policy can only be observed, but are never verifiable. Accordingly, a political information market is used to produce verifiable information in the form of prices at a time when policy results are not observable.

There is extensive literature on incentive contracts in general. The analysis of incentive problems in the classical principal-agent framework started with Mirrlees (1976), Holmström (1979), and Grossman and Hart (1983). One can distinguish incentive schemes based on objective performance measurement (see e.g., Baker 1992 and Lazear 2000) and incentive mechanisms based on subjective performance assessments (see e.g., Gibbons 1998). We are using an objective performance measure, as we make payment dependent on the price on the information market in this paper. ${ }^{6}$

Political information markets have attracted much attention recently. Information markets have been suggested to improve public policy decisions (see e.g., the recent surveys and discussions by Hahn and Tetlock (2004), Wolfers and Zitzewitz (2004), or by Hanson (2003), who suggests using information markets to select policies expected to raise GDP). The basic idea behind information markets is the accumulation of scattered information to predict uncertain future events. Political information markets have turned out to be very successful in predicting election results (see e.g., Berg et al. 1996 or Berlemann and Schmidt 2001). We use information markets to estimate the performance on which politicians' pensions depend. In a companion paper, Gersbach and Müller (2006) show that a combination of democratic elections, informations markets, and reelection threshold contracts can be used to motivate politicians to undertake efficient long-term policies in cases where their performance is not verifiable.

\footnotetext{
${ }^{6} \mathrm{Of}$ course, the price on the information market is generated on the basis of subjective assessments by investors.
} 


\section{The basic model}

We consider a political agency problem with asymmetric information regarding the incumbent's decision about running for reelection. There are two periods denoted by $t=1,2$. The public consists of a large number of homogeneous voters. A representative voter is denoted by $v$.

\subsection{The effort decision}

We assume that there is one risk-neutral incumbent in office who has to decide the level of effort to spend on a task creating a public project in period 1 . The chosen amount of effort in period 1 is denoted by $e$. We assume that due to physical constraints there is an upper bound $\bar{e}>0$ such that $0 \leq e \leq \bar{e}$. We use $b$ to denote the social benefits per capita deriving from the expenditure of effort and assume that they are proportional to the amount of effort, i.e.,

$$
b=k \cdot e
$$

with $0<k<1$. On the other hand exerting effort is costly for a politician. Effort $e$ in period 1 is associated with costs $c e^{2}$ for the incumbent. The factor $c$ (where $c>0$ ) can be interpreted as the competence of the incumbent. A small value for $c$ is equivalent to high competence, i.e., undertaking a given project does not result in high effort costs for the politician. We will use the standard rule to break ties. If the incumbent is indifferent as to two effort options, he will choose the amount of effort that leads to higher social welfare.

\subsection{The utility}

We use $W_{t}$ to denote the utility from holding office in period $t$. The variable $m$ denotes the level of the pension the politician will receive in period 2 if period 1 is his last term in office. We start with a fixed pension scheme where pensions are fixed to $\bar{m}$ and $\bar{m}>0$.

At the beginning of period 1, the incumbent observes the utility he would derive from holding office in the next period. This can either be low utility $\underline{W}_{2}$ or high utility $\bar{W}_{2}$. The a priori probability that the incumbent will obtain $\underline{W}_{2}$ in the next period is $q$ (where $0<$ $q<1$ ), while the probability of obtaining $\bar{W}_{2}$ is $1-q$. We assume that $q$ is common knowledge. There are a variety of reasons why $W_{2}$ may be stochastic. For instance, an incumbent may be physically exhausted so that staying in office would be a risk to his health. Also, challengers in his own party may threaten to make life in office difficult for the politician. Finally, the incumbent may forgo other career opportunities if he stays in office.

The incumbent will run for reelection if and only if his utility from holding office in the next period is at least as large as his outside option, which consists of his pension. We assume that $\bar{W}_{2} \geq \bar{m}$ and that $\underline{W}_{2}<\bar{m}$. Thus, at the end of period 1 the incumbent will run for reelection if he observes $\bar{W}_{2}$, while he will not want to run for reelection if he observes $\underline{W}_{2}$.

We assume that - just like every other citizen - the politician receives per capita benefits $b=k e$. We use $r_{1}$ to denote the incumbent's probability of getting reelected at the end of period 1 and $\delta$ to denote his discount factor $(0<\delta<1)$. As $W_{1}$ (i.e., the utility from holding office in period 1) is sunk when the politician chooses his amount of effort, we will neglect $W_{1}$ in the subsequent analysis. The remaining utility of incumbent $i$ is denoted by $U_{i}$. After he has learned $W_{2}, U_{i}$ is either

$$
U_{N R}^{i}=k e-c e^{2}+\delta \bar{m}
$$


if he knows that he will not run for reelection $\left(W_{2}=\underline{W}_{2}\right)$ or

$$
U_{R}^{i}=k e-c e^{2}+\delta\left[\left(1-r_{1}\right) \bar{m}+r_{1} \bar{W}_{2}\right]
$$

in the case where he knows that he will run for reelection $\left(W_{2}=\bar{W}_{2}\right)$.

It is obvious that the incumbent will never choose $e=0$, as he benefits from the public project. Finally, we make the following assumption:

$$
\bar{e} \geq \frac{k}{2 c}+\sqrt{\frac{\delta \bar{W}_{2}}{c}} .
$$

This assumption ensures that the incumbent will never want to choose a corner solution. ${ }^{7}$ Accordingly, we can concentrate on interior solutions.

The expected utility function of a representative voter $v$ is: ${ }^{8}$

$$
U^{v}=b
$$

\subsection{The information structure}

We assume that at the beginning of period 1 the incumbent knows whether he will run for reelection at the end of this period or whether this will be his final term in office. However, he will not yet disclose this to the public in order to avoid a loss of political power (in particular in his own party). In politics, an incumbent who is known not to be seeking reelection but continuing to hold office up to the election date is called a lame duck. ${ }^{9}$ In extreme cases incumbents known to be lame ducks are unable to implement any more projects during the remainder of their final term.

We assume that voters are able to perfectly observe the value of $b$ at the date of the reelection decision and can thus perfectly infer $e$. We assume that, in contrast to ordinary voters, investors receive early signals about the performance of the politician. ${ }^{10}$ In particular, each investor $j$ obtains a noisy signal $\beta_{j}$ before the incumbent informs the public about whether he will run for reelection or not. We assume that signal $\beta_{j}$ is given as

$$
\beta_{j}=b+\varepsilon_{j}
$$

where the error term $\varepsilon_{j}$ is a random variable with support $[-a ; a](a>0)$, distributed with the density function $f(\varepsilon)$ and $E(\varepsilon)=0$. Thus the signal $\beta$ is distributed with the density function $f(\beta)=f(b+\varepsilon)$ on $[b-a ; b+a]$ and $E(\beta)=b .^{11}$

\footnotetext{
${ }^{7}$ This is shown in Appendix B.

${ }^{8}$ Note that we disregard the wage and pension costs of the politician in the utility function of the voters, which is a good approximation if the number of voters is large.

${ }^{9}$ The "lame duck" phenomenon is well documented in the literature (see e.g., Millimet et al. 2004).

${ }^{10}$ One could assume that investors spend time on collecting information concerning the quality of the incumbent's policy and thus obtain such knowledge earlier than ordinary voters.

${ }^{11}$ Note that any signal $\beta_{j}<0$ will be interpreted as $b=0$ and that any signal $\beta_{j}>k \bar{e}$ will be interpreted as $b=k \bar{e}$.
} 


\subsection{The reelection scheme}

In modeling reelections, we have to look only at the case where the incumbent runs for office again. Voters are assumed to make their reelection decisions dependent on expected benefit and thus on the effort the politician has exerted. From the perspective of the incumbent at the beginning of period 1 , the probability $r_{1}$ that the politician will be reelected when he runs for reelection and voters observe effort $e$ is assumed to be given by

$$
r_{1}(e)= \begin{cases}0 & \text { if } e=0 \\ \phi e & \text { if } 0<e<\bar{e} \\ 1 & \text { if } e=\bar{e}\end{cases}
$$

where $\phi=\frac{1}{\bar{e}}>0$. Note that the incumbent will never get reelected if he exerts no effort at all and that he will get reelected with certainty only if he chooses the maximum possible amount of effort.

The fact that reelection probability depends monotonically on $e$ can be interpreted as a mixture of prospective and retrospective voting behavior (see Gersbach and Liessem 2008 for detailed justification and discussion). The essential assumption is that the reelection scheme is a continuous function of effort.

\subsection{Summary}

The timing of the game is summarized in Fig. 1.



Fig. 1 Timeline with fixed pensions 


\section{Results under fixed pensions}

In this section we assume that the amount of the pension is fixed at $\bar{m}$. Recall that we assume that $\bar{m} \leq \bar{W}_{2}$, as otherwise incumbents would never aspire to get reelected.

\subsection{First-best solution}

We start by characterizing the first-best solution. To derive the first-best solution we assume that the public observes the realization of $W_{2}$ and can write a forcing contract contingent on $W_{2}$ and on the effort level. If the incumbent fulfills the contract, he will be reappointed (in case $W_{2}=\bar{W}_{2}$ ) or he receives the fixed pension $\bar{m}$ (in case $W_{2}=\underline{W}_{2}$ ). There are no elections. We denote the first-best amount of effort by $e_{R}^{f i x, F B}$ if $\bar{W}_{2}$, and by $e_{N R}^{f i x, F B}$ if $\underline{W}_{2}$.

Proposition 1 The first-best amount of effort is given by

$$
\begin{aligned}
& e_{R}^{f i x, F B}=\frac{k}{2 c}+\sqrt{\frac{\delta \bar{W}_{2}}{c}}, \\
& e_{N R}^{f i x, F B}=\frac{k}{2 c}+\sqrt{\frac{\delta \bar{m}}{c}} .
\end{aligned}
$$

The proof is given in the Appendix. First-best efforts are given straightforwardly by the maximum effort at which the politician is indifferent between exerting first-best effort and renouncing the contract. Note that the first-best solution is achieved e.g., by the following punishment scheme:

- If the incumbent wants to stay in office and chooses a lower level of effort than $e_{R}^{f i x, F B}$, then he will not be re-appointed.

- If the incumbent wants to retire and chooses a lower level of effort than $e_{N R}^{f i x, F B}$, then he will receive no pension.

Such harsh punishment would require that the public was able to observe $W_{2}$, which, however, is private information in our model. In the following, we assume that voting is given by (7), which we discussed in Sect. 3.4. ${ }^{12}$

\subsection{Fixed pensions and the reelection mechanism}

In this subsection we derive subgame-perfect equilibria for the game in the case where reelection takes place or the politician opts for a fixed pension scheme.

As the politician knows whether he will run for reelection or not at the date when he chooses his amount of effort, two incentive constraints are important: $I C_{R}^{f i x}$ when the politician runs for reelection and $I C_{N R}^{f i x}$ when he does not.

The incentive constraints are given as follows:

$$
\begin{aligned}
& I C_{R}^{f i x} \quad e=\arg \max _{e}\left\{k e-c e^{2}+\delta\left[r_{1} \bar{W}_{2}+\left(1-r_{1}\right) \bar{m}\right]\right\}, \\
& I C_{N R}^{f i x} \quad e=\arg \max _{e}\left\{k e-c e^{2}+\delta \bar{m}\right\} .
\end{aligned}
$$

\footnotetext{
${ }^{12}$ We would like to stress that a purely retrospective voting scheme, i.e., a threshold voting scheme, would also be an equilibrium response of voters in our model.
} 
We start with the case where the politician does not run for reelection.

Proposition 2 In the case where the politician knows that he will not run for reelection, his effort choice is

$$
e_{N R}^{f i x}=\frac{k}{2 c}
$$

Similarly, we obtain

Proposition 3 In the case where the politician knows that he will run for reelection, his effort choice under the reelection scheme $r_{1}$ is

$$
e_{R}^{f i x}=\frac{k+\delta \phi\left(\bar{W}_{2}-\bar{m}\right)}{2 c} .
$$

The incumbent's effort choice under the reelection mechanism is lower than in the firstbest solution for two reasons. If the politician does not want to run for reelection, fixed pensions do not create incentives to work hard and the effort choice is determined solely by personal benefits. If the politician runs for reelection, he has a chance of staying in office by exerting less effort than in the first-best solution, which in turn induces him to do so.

\section{Corollary 1}

(i) $e_{N R}^{f i x}<e_{N R}^{f i x, F B}$.

(ii) $e_{R}^{f i x}<e_{R}^{f i x, F B}$.

The proof of Corollary 1 is given in the Appendix.

\section{The model with flexible pensions}

In the following, we introduce information markets and flexible pensions to investigate whether such a scheme can improve welfare.

\subsection{The information market}

We introduce a political information market that is organized in the first period, after the incumbent has chosen his amount of effort, but before he announces whether he will run for reelection. ${ }^{13}$ We assume that there is an uneven number $N$ of potential investors and that each investor is allowed to trade only up to $\bar{s}$ assets. ${ }^{14}$ We assume that $\bar{s}$ is not too large, so that no investor is liquidity-constrained. Investors are assumed to be a small group of the

\footnotetext{
${ }^{13}$ Note that at this point of time, there will usually be uncertainty about the opponent in the reelection race. Then participants in the information market will evaluate the reelection chances of the incumbent against an unknown opponent. Such markets are already used in practice, e.g., there is a market which predicts the chances of a candidate for becoming President of the United States versus an unknown opponent.

${ }^{14}$ It makes sense to restrict trade in such information markets to individuals and to limit trading volume per person to avoid large-scale manipulation attempts.
} 
electorate, so they have no influence on the voting outcome. Investors are assumed to be risk-neutral and have the following utility:

$$
U_{j}\left(Y_{j}\right)=Y_{j},
$$

where $Y_{j}$ is gain or loss in the information market. ${ }^{15}$ Investor $j$ obtains a signal $\beta_{j}$ and uses this signal to assess whether the politician is likely to get reelected or not.

There are two assets $D$ and $E$. If the politician is successfully reelected, then the owners of asset $D$ receive one monetary unit per unit of $D$. If the politician stands for reelection but is not reelected, then the owners of asset $E$ receive one monetary unit per unit of $E$. If the politician does not run for reelection, the market will be neutralized, i.e., each investor will be paid back the money he has invested. ${ }^{16}$ The entire information market works as follows: A bank or an issuer offers an equal amount of assets $D$ and $E$. On the secondary market, traders can buy assets $D$ or $E .{ }^{17}$ Trading in the secondary market results in a price $p$ for one unit of asset $D$. As buying one unit of $D$ and one unit of $E$ pays one monetary unit with certainty, no arbitrage implies that the price of asset $E$ must be $1-p$. Otherwise either traders or the issuer could make riskless profits. An equilibrium in the information market is a price $p^{*}$ such that traders demand an equal amount of assets $D$ and $E$.

If the incumbent runs for reelection but loses to the rival candidate, his pension may be based either on the price in the information market or on the election result. When the information market works perfectly and correctly predicts the result of the next election, both measures are identical, and we will use the market price as a reference base for the determination of the pension, including the case where an incumbent loses.

It is useful to look more closely at the event tree associated with the assets. If, for example, an investor buys one unit of asset $D$ at price $p$, then the event tree, the payoffs on the information market, and the pension of the incumbent are given in Fig. 2.

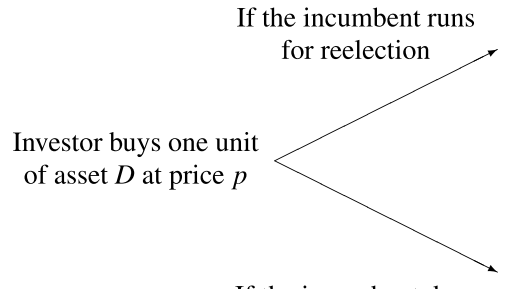

If the incumbent does not run for reelection



Investor receives $p$ pension is $m(p)$

Fig. 2 Event tree

\footnotetext{
${ }^{15}$ Note that we neglect the utility from the chosen effort of the politician in the utility function of the investors, as policy outcomes have no influence on the trading behavior of the investors.

${ }^{16}$ Note that the politician may use his information about the fact whether he will run for reelection to make riskless profits in the information market. At the moment, we assume that politicians are not allowed to trade in the information market to solve this problem. In the extensions, we will offer alternative solutions.

${ }^{17}$ We could allow for short-selling, but this is immaterial to our analysis.
} 


\subsection{Flexible pensions}

Our central assumption is that the level of pension $m$ depends positively on price $p$ on the information market predicting the probability that the incumbent will be reelected. The basic idea is the following: If the incumbent has performed well during his last term and his reelection chances are high, price $p$ will be high, and this will yield a larger pension. Through price $p$ the pension will depend on the effort exerted by the politician. We maintain our assumption that the incumbent will run for reelection if and only if he observes $\bar{W}_{2}$ to be his utility from office in period 2 . The formal version of the necessary conditions for this assumption will be given in the next section.

\subsection{Summary}

The timing of the whole game, including information markets and flexible pensions, is summarized in Fig. 3.



Fig. 3 Timeline with flexible pensions

\section{Results under flexible pensions}

In this section we derive the main results when flexible pensions are used.

\subsection{Pricing on the information market}

In the first step we determine the equilibrium price in the information market. An investor $j$ with signal $\beta_{j}$ takes into account his own information and the information the market price reveals. A standard way of modeling the information aggregation process is as follows:

$$
\operatorname{Pr}_{j}(R E \mid p)=z \operatorname{Pr}_{j}\left(R E \mid \beta_{j}\right)+(1-z) p .
$$


$\operatorname{Pr}_{j}(R E \mid p)$ is the probability assessment of investor $j$ on the chances that the incumbent will be reelected, where $z$ (with $0 \leq z \leq 1$ ) is a weighting term describing self-assessed confidence, i.e., the subjective confidence of an investor in his own signal $\beta_{j}$ relative to the market belief expressed by price $p .{ }^{18}$ We assume that $z$ is the same across all investors.

We next derive the investor's reelection assessment for the incumbent. As $e=\frac{b}{k}$ and $r_{1}(e)=\phi e$ and taking into account the boundary conditions, we obtain

$$
\operatorname{Pr}_{j}\left(R E \mid \beta_{j}\right)= \begin{cases}0 & \text { if } \frac{\phi}{k} \beta_{j}<0, \\ \frac{\phi}{k} \beta_{j} & \text { if } 0 \leq \frac{\phi}{k} \beta_{j} \leq 1, \\ 1 & \text { if } \frac{\phi}{k} \beta_{j}>1 .\end{cases}
$$

Given price $p$ and belief $\beta_{j}$, an investor $j$ maximizes

$$
\max _{d_{j}} E U_{j}=(1-q)\left[\operatorname{Pr}_{j}(R E \mid p)\left(d_{j}(1-p)\right)+\left(1-\operatorname{Pr}_{j}(R E \mid p)\right)\left(-d_{j} p\right)\right]+q \cdot 0
$$

where $-\bar{s} \leq d_{j} \leq \bar{s}$. If $d_{j}$ is positive, investor $j$ wants to buy $d_{j}$ units of asset $D$. If $d_{j}$ is negative, investor $j$ wants to buy $d_{j}$ units of asset $E$. We obtain

$$
\frac{\partial E U_{j}}{\partial d_{j}}=(1-q)\left[\left(z \operatorname{Pr}_{j}\left(R E \mid \beta_{j}\right)+(1-z) p\right)(1-p)-\left(1-z \operatorname{Pr}_{j}\left(R E \mid \beta_{j}\right)-(1-z) p\right) p\right] \text {. }
$$

The derivative of the expected utility regarding $d_{j}$ does not depend on $d_{j}$, so each investor will choose a corner solution. If his signal $\beta_{j}$ is larger than the median signal, which is denoted by $\beta_{j}^{m}$, then he will buy the largest possible amount of assets $D$, i.e., $d_{j}=\bar{s}$. If his signal $\beta_{j}$ is smaller than $\beta_{j}^{m}$, then he will buy the largest possible amount of assets $E$, i.e., $d_{j}=-\bar{s}$. As all investors will buy the largest allowed amount of assets, the number of investors who want to buy assets $D$ is equal, in equilibrium, to the amount of investors who want to buy assets $E$. Accordingly we obtain the following proposition:

\section{Proposition 4}

(i) There is a unique equilibrium in the information market given by

$$
p^{*}=\frac{\phi \beta_{j}^{m}}{k} .
$$

(ii) The expected price $p^{* E}$ is given by

$$
p^{* E}=\frac{e}{\bar{e}}
$$

The proof is given in the Appendix. The expected price $p^{* E}$ is given by the ratio of the effort $e$ that the incumbent actually exerts and the maximum effort level $\bar{e}$. Note that $0 \leq$ $p^{* E} \leq 1$ and that the expected equilibrium price depends positively on $e$. If the incumbent chooses more effort $e$, the expected signal $E\left[\beta^{m}\right]$ will increase, which in turn raises $p^{* E}$. This property will be used to design a flexible pension scheme in the next subsection.

\footnotetext{
${ }^{18}$ For a statistical foundation see Morris (1983) and Rosenblueth and Ordaz (1992). This information aggregation procedure is also used in Wolfers and Zitzewitz (2006) and Gersbach and Müller (2006).
} 
6.2 Linear dependence of pension and effort

We next introduce flexible pensions in the form of a two-part scheme:

$$
m=m^{0}+\alpha p^{*}
$$

Thus, the pension scheme is composed of a constant part $m^{0}$ where $0 \leq m^{0} \leq \bar{m}$, and of a flexible part that depends in a linear way on the price in the information market with $\alpha>0$. The expected pension $m^{E}$ for the politician depends on the expected equilibrium price and is thus given by

$$
m^{E}=m^{0}+\alpha p^{* E} .
$$

We construct the pension scheme in such a way that the expected flexible part of the pension that is paid in the case of the highest possible effort is equal to $\bar{m}$. This requires

$$
\alpha \frac{\bar{e}}{\bar{e}}=\bar{m}
$$

which yields $\alpha=\bar{m}$ and

$$
m^{E}=m^{0}+\bar{m} \frac{e}{\bar{e}} .
$$

We define $\lambda:=\frac{\bar{m}}{\bar{e}}$ and obtain

$$
m^{E}=m^{0}+\lambda e .
$$

Finally, using $\bar{e}=\frac{1}{\phi}$ leads to

$$
\lambda=\phi \bar{m} .
$$

To ensure that the incumbent will run for reelection if and only if he observes $\bar{W}_{2}$, we sharpen our technical assumptions concerning $\bar{W}_{2}$ and $\underline{W}_{2}$. We assume that $\bar{W}_{2} \geq \bar{m}+m^{0}$, which ensures that $0 \leq m^{E}(e) \leq \bar{W}_{2}$ for all feasible values of $e$. Furthermore, we assume that $\underline{W}_{2}<0$.

We again have to distinguish two cases. Either the politician decides that he will run for reelection $\left(I C_{R}^{f l e x}\right)$ or he decides to drop out $\left(I C_{N R}^{f l e x}\right)$. The optimum effort choices in both cases follow from the incentive constraints:

$$
\begin{aligned}
& I C_{R}^{f l e x} \quad e=\arg \max _{e}\left\{k e-c e^{2}+\delta\left[r_{1} \bar{W}_{2}+\left(1-r_{1}\right) m^{E}(p(e))\right]\right\} \\
& I C_{N R}^{f l e x} \quad e=\arg \max _{e}\left\{k e-c e^{2}+\delta m^{E}(p(e))\right\} .
\end{aligned}
$$

We start with the latter case and obtain

Proposition 5 When the politician knows that he will not run for reelection, he chooses

$$
e_{N R}^{f l e x}=\frac{k+\delta \lambda}{2 c}
$$

The proof of Proposition 5 is given in the Appendix. The former case yields 
Proposition 6 In the case where the politician knows that he will run for reelection, his effort choice under a system with flexible pensions will be the following:

$$
e_{R}^{f l e x}=\frac{k+\delta \lambda+\delta \phi\left(\bar{W}_{2}-m^{0}\right)}{2 c+2 \delta \phi \lambda} .
$$

The proof of Proposition 6 is given in the Appendix. It follows immediately from Proposition 6 that the amount of effort is decreasing in $m^{0}$, which is the fixed part. The intuition for this result is as follows: The disciplining effect of the reelection mechanism becomes weaker when the gap between the pension and $\bar{W}_{2}$ becomes smaller. As the spread decreases with $m^{0}$, the result follows.

\subsection{Welfare effects}

In the following, we analyze two polar cases in order to shed light on the welfare effects of flexible pensions. The pure flexible pensions system is $m^{0}=0$. This represents a scheme where the incumbent receives no pension when he exerts no effort and where the highest possible pension for him is equal to $\bar{m}$. Hence, in comparison to the system with fixed pensions, this is a pure penalty system. The other polar case is $m^{0}=\bar{m}$, which represents a pure bonus system where the incumbent is never worse off in comparison to the fixed pension scheme.

We compare the pure penalty and the pure bonus system with fixed pensions and start with the case where the incumbent is not running for reelection:

Proposition 7 If the incumbent is not running for reelection, then the amount of effort under flexible pensions is strictly larger than it is under fixed pensions for any $m^{0}$ where $0 \leq$ $m^{0} \leq \bar{m}$.

This result follows directly from Propositions 2 and 5. This result is intuitively clear. Under a scheme with fixed pensions, the only motive to exert effort for an incumbent who knows that he will not run for reelection is private utility from policy projects. Under the two-part pension scheme, a higher effort choice increases his pension, and the politician has larger benefits from exerting effort, which in turn increases public welfare. Note that Proposition 7 holds for all types of two-part flexible pension schemes.

Now we look at the case where the politician knows that he will run for reelection. Here it will be important to distinguish pure penalty and pure bonus systems. We start with the former.

Proposition 8 If the incumbent runs for reelection and if $m^{0}=0$, then the amount of effort under flexible pensions will always be weakly larger than it is under fixed pensions.

Propositions 7 and 8 imply that a pure penalty pension scheme is weakly welfareimproving in all cases. However, pure penalty schemes are difficult to use in practice. Hence we next consider a pure bonus system.

Proposition 9 If the incumbent runs for reelection and if $m^{0}=\bar{m}$, then the level of effort under flexible pensions will be smaller than the level of effort under fixed pensions if and only if

$$
\bar{W}_{2}-\bar{m}>\frac{c-k \phi}{\delta \phi^{2}} .
$$


Thus flexible pensions are not always welfare-enhancing if $m^{0}=\bar{m}$. The intuition for the result that flexible pensions may decrease welfare is as follows: On the one hand, a system with flexible pensions motivates the incumbent ceteris paribus to choose a higher amount of effort, as this increases his pension in the case where he loses the reelection. On the other, flexible pensions result ceteris paribus in a lower effort choice by the incumbent, as the disciplining effect of the reelection mechanism becomes weaker when the gap between the pension and $\bar{W}_{2}$ narrows. If the latter effect is larger, then flexible pensions under a pure bonus system will result in a lower effort choice than fixed pensions. It is obvious that the latter effect is growing in $m^{0}$, and this explains our result that the positive welfare effects of flexible pensions are decreasing in $m^{0}$. As we see in condition (30) flexible pensions will tend towards being worse than fixed pensions if the gap between $\bar{W}_{2}$ and $\bar{m}$ is large, which means that the motivation due to the reelection mechanism is substantial.

Finally, we determine the scheme of flexible pensions with the highest value of $m^{0}$ that is universally welfare-enhancing, i.e., we determine a critical value, denoted by $m^{\text {crit }}$, such that flexible pensions are always welfare-improving for all $m^{0}<m^{\text {crit }}$. We obtain

Proposition 10 There exists a $m^{\text {crit }}>0$ such that for all $m^{0} \leq m^{\text {crit }}$ flexible pensions are weakly welfare-increasing in comparison to fixed pensions. This critical value is given by

$$
m^{c r i t}=2 \bar{m}-\frac{k \lambda+\delta \phi \lambda\left(\bar{W}_{2}-\bar{m}\right)}{c} .
$$

The proof of Proposition 10 is given in the Appendix. Proposition 10 shows that a pension scheme using $m^{0}<m^{\text {crit }}$ is always weakly welfare-increasing.

\section{Practical considerations}

In this section we will address several issues concerning the practical implementation of our proposal.

\subsection{Choice between fixed and flexible pensions}

It is conceivable that an incumbent is not planning to run for reelection, and would like to make unpopular decisions which he perceives to be desirable in the long-term. Flexible pensions might deter an incumbent from undertaking such long-term projects. This problem might be solved as follows: Already at the beginning of his term, the incumbent has the opportunity to announce that this will be his final term in office. If he does so, then he receives a fixed pension. Otherwise he will be subject to the flexible pension scheme. Thus, the incumbent can choose between early and late announcement, linked to the corresponding pension scheme. ${ }^{19}$

\subsection{Preventing manipulations by the incumbent}

As mentioned above, the incumbent may have incentives to manipulate the information market in the following way: Suppose he knows that he will not run for reelection. Then he has an incentive to buy large amounts of assets $D$ in order to trigger a higher equilibrium price,

\footnotetext{
${ }^{19} \mathrm{An}$ analysis of such schemes is left to future research.
} 
as this would raise his pension. As the politician knows that the information market will be neutralized and that amounts invested will be paid back, the gains in terms of pensions are riskless. This is a serious concern.

The most obvious way to prevent this is to prohibit trading by politicians and to punish the use of stooges. However, such prohibitions may be not sufficient to prevent manipulations. In the following, we briefly discuss two possibilities to ensure that the incumbent is not interested in manipulating the market.

First, one should use an average price calculated over a long time-span to determine the incumbent's pension. This is possible, since a flexible pension scheme will be applied only when the announcement not to run for reelection occurs late in the term, e.g., two or three years after the term has started. Hence, there is a time span of two or three years for which the average price in the information market can be used to determine the pension. If an average price is used to determine the pension, an incumbent who wants to raise his pension would be forced to manipulate the price in the information market every day, which would become very costly over time.

Second, one could renounce neutralization when the incumbent is not running for reelection. If investors receive nothing if an incumbent does not run for reelection, ${ }^{20}$ the incumbent has no incentive to manipulate the market in the way described above. With such a scheme of non-neutralization, prices $p_{D}$ and $p_{E}$ for assets $D$ and $E$ will be lower, ${ }^{21}$ as investors have to take into account the case where they lose their invested money if the incumbent is not running for reelection. In such cases, one uses the ratio $\frac{p_{D}}{p_{E}}$ for the variable part of a flexible pension scheme.

Renouncing neutralization makes manipulations by the incumbent extremely costly and will deter him from such activities, as long as the trading volume on the market is sufficiently large. The intuition runs as follows: Suppose the incumbent wants to boost the equilibrium market price from $p^{*}$ to a higher price, say $p^{+}$. Then he must pay $2 \bar{s}$ times the number of investors who receive signals that suggest a reelection probability in the interval $\left[p^{*}, p^{+}\right]$in the equilibrium without manipulation. ${ }^{22}$ If there are many investors, manipulations to induce a large difference $p^{+}-p^{*}$ will become very costly, as all money spent for additional assets $D$ is lost for the incumbent.

The best possible way is to combine average prices and non-neutralization to deter incumbents from manipulating the information market.

\subsection{Term limits}

As already mentioned, our proposal cannot be applied when there are term limits, since the information market will not work if it is certain that the incumbent is in his last term. In this case, one may conceive other ways to make pensions dependent on performance in the last term. For instance, one could make the pension depend on the vote-share the incumbent's party will receive in the next election. As long as voters punish or reward parties for the behavior of their past officeholders, ${ }^{23}$ such a scheme would have effects similar to the ones

\footnotetext{
${ }^{20}$ One might assume that the money is used as revenues for the government, e.g., it might be used to finance the pensions of politicians.

${ }^{21}$ Note that $p_{D}$ and $p_{E}$ will no longer add to 1 .

${ }^{22}$ The reason is as follows: Investors in the interval $\left[p^{*}, p^{+}\right]$originally buy assets $D$, but if the price is boosted to $p^{+}$, they switch and buy assets $E$. Thus, to induce an equilibrium price $p^{+}$, the incumbent has to buy an amount of assets $D$ equal to the excess demand of assets $E$ by private investors.

${ }^{23}$ Empirical evidence for a positive link between economic performance and election prospects for the incumbent party has been provided e.g., by Fair (1996) and Hibbs (2000).
} 
of flexible pension schemes. Making pensions dependent on the future vote-share of the ruling party would be applicable even in the case of binding term limits.

\subsection{Balanced budgets}

A useful extension is to explore budget-neutral design of flexible pensions, i.e., to impose the requirement that expected expenditures are equal under flexible and under fixed pensions. One might argue that the public does not want to spend more on flexible pensions than on fixed ones. We start by explicitly introducing the salary of politicians in office, denoted by $S$, which is assumed to be fixed. Total benefits $W_{2}$ are then composed of $S$ and a personal, non-monetary benefit from holding office, denoted by $P_{2} . P_{2}$ is either $\underline{P}_{2}<0$ or $\bar{P}_{2}>0$, such that $\bar{W}_{2}=S+\bar{P}_{2}$ and $\underline{W}_{2}=S+\underline{P}_{2}$ are the two possible realizations of utilities of the incumbent. We use $r_{1}^{f i x}$ and $r_{1}^{\text {flex }}$ to denote reelection probability depending on the pension scheme. The flexible pension scheme is given by $m=m^{0}+\mu e$, where $m^{0}$ and $\mu$ (with $\mu>0)$ are treated as variables selected by the public. The public's problem is given by: ${ }^{24}$

$$
\max _{m^{0}, \mu} q e_{N R}^{f l e x}+(1-q) e_{R}^{f l e x}
$$

subject to

$$
\begin{aligned}
q\left(m^{0}+\mu e_{N R}^{f l e x}\right)+(1-q)\left[r_{1}^{f l e x} S+\right. & \left.\left(1-r_{1}^{f l e x}\right)\left(m^{0}+\mu e_{R}^{f l e x}\right)\right]=q \bar{m}+(1-q)\left[r_{1}^{f i x} S+\left(1-r_{1}^{f i x}\right) \bar{m}\right], \\
e_{N R}^{f l e x} & =\frac{k+\delta \mu}{2 c}, \\
e_{R}^{f l e x} & =\frac{k+\delta \mu+\delta \phi\left(\bar{P}_{2}+S-m^{0}\right)}{2 c+2 \delta \phi \mu}, \\
r_{1}^{f x} & =\phi \frac{k+\delta \phi\left(\bar{P}_{2}+S-\bar{m}\right)}{2 c}
\end{aligned}
$$

and

$$
r_{1}^{f l e x}=\phi \frac{k+\delta \mu+\delta \phi\left(\bar{P}_{2}+S-m^{0}\right)}{2 c+2 \delta \phi \mu} .
$$

Note that the public aims at maximizing the expected effort under the flexible pension scheme, subject to the requirement that the expected remuneration of the politician is the same under flexible and under fixed pensions. The optimization problem yields a unique solution involving $m^{0}=0$. The solution for $\mu$ is straightforward, but tedious to calculate and therefore omitted.

\subsection{Outside influences}

In practice, the reelection probability of the incumbent will not only depend on his amount of effort, as there are many other influences beyond the incumbent's control. However, as long as the incumbent can affect his reelection chances by working harder, our solution can work. Moreover, the use of a longer time-span to calculate the average price for determining the pension diminishes the impact of a single factor outside the control of officeholders.

\footnotetext{
${ }^{24} \mathrm{We}$ focus on parameter constellations where interior solutions hold.
} 


\section{Conclusion}

In this paper we have suggested a new procedure for solving the motivation problem of a politician in his last term. Several useful extensions of our model might be pursued in future research. For example, the model could be enriched by considering a heterogeneous electorate and interest groups lobbying for particular policies. Such an extension might strengthen the value of our mechanism, as politicians are less vulnerable to outside influence when their pensions are at stake. Moreover, we have suggested a mechanism mitigating the motivation problem of an incumbent knowing he is in his final term, but having the same interests in policies as voters. Of course, incentive schemes may backfire as they may have unintended consequences. Which types of unintended consequences of flexible pension schemes exist and how they can be remedied is left for future research.

Acknowledgement We would like to thank Johannes Becker, Peter Bernholz, Volker Hahn, Panu Poutvaara, two referees and seminar participants in Basel, Jena and Zurich for many helpful comments.

\section{Appendix A: Proofs}

Proof of Proposition 1 The public maximizes its utility subject to the incumbent still wanting to enter into the contract. If the incumbent does not enter into the contract and will neither receive a pension nor be reelected after completion of his current term, then he would maximize $k e-c e^{2}$, which yields $e=\frac{k}{2 c}$. In this case his utility is equal to $\frac{k^{2}}{4 c}$.

If $W_{2}=\bar{W}_{2}$ and the incumbent wants to stay in office, the problem of the public is given by

$$
\begin{aligned}
& \max U^{v}=b, \\
& \text { s.t. } \quad \delta \bar{W}_{2}+k e-c e^{2} \geq \frac{k^{2}}{4 c} .
\end{aligned}
$$

As $\frac{\partial b}{\partial e}>0$, condition (34) will hold with equality, which yields

$$
e_{1 / 2}=\frac{k}{2 c} \pm \sqrt{\frac{\delta \bar{W}_{2}}{c}} .
$$

Hence the public will demand the highest possible amount of effort

$$
e_{R}^{f i x, F B}=\frac{k}{2 c}+\sqrt{\frac{\delta \bar{W}_{2}}{c}} .
$$

The proof in the case where the incumbent does not want to run for reelection is analogous and is therefore omitted here.

Proof of Proposition 2 The incumbent has the following utility function:

$$
U_{N R}^{f i x}=k e-c e^{2}+\delta \bar{m} .
$$


The first-order condition $\frac{\partial U_{N R}^{f i x}}{\partial e}=k-2 c e=0$ implies $e_{N R}^{f i x}=\frac{k}{2 c}$. According to our assumptions, we have $\frac{k}{2 c} \leq \bar{e}$, so the solution is feasible. Note that the incumbent will never choose $e=0$, as his utility would be equal to $\delta \bar{m}$, which is smaller than $U_{N R}^{f i x}\left(\frac{k}{2 c}\right)=\frac{k^{2}}{4 c}+\delta \bar{m}$.

Proof of Proposition 3 The incumbent has the following utility function:

$$
U_{R}^{f i x}=k e-c e^{2}+\delta\left[r_{1} \bar{W}_{2}+\left(1-r_{1}\right) \bar{m}\right] .
$$

The first-order condition amounts to

$$
\frac{\partial U_{R}^{f i x}}{\partial e}=k-2 c e+\delta \frac{\partial r_{1}}{\partial e} \bar{W}_{2}-\delta \frac{\partial r_{1}}{\partial e} \bar{m}=0 .
$$

Using $\frac{\partial r_{1}}{\partial e}=\phi$, we obtain

$$
k-2 c e+\delta \phi\left(\bar{W}_{2}-\bar{m}\right)=0
$$

which yields $e_{R}^{f i x}=\frac{k+\delta \phi\left(\bar{W}_{2}-\bar{m}\right)}{2 c}$. Note that $e_{R}^{f i x}>0$ since $\bar{W}_{2} \geq \bar{m}$. Furthermore, we have $U_{R}^{f i x}\left(\frac{k+\delta \phi\left(\bar{W}_{2}-\bar{m}\right)}{2 c}\right)=\frac{\left[k+\delta \phi\left(\bar{W}_{2}-\bar{m}\right)\right]^{2}}{4 c}+\delta \bar{m}>\delta \bar{m}=U_{R}^{f i x}(0)$. Thus the politician will always prefer $e_{R}^{f i x}$ over $e=0$. Finally, according to our assumptions we have $e_{R}^{f i x} \leq \bar{e}$.

Proof of Corollary 1 We have $e_{N R}^{f i x}=\frac{k}{2 c}<\frac{k}{2 c}+\sqrt{\frac{\delta \bar{m}}{c}}=e_{N R}^{f i x, F B}$ in the case where the politician is not running for reelection.

In the case where the politician is running for reelection, we have to show that $e_{R}^{f i x, F B}>e_{R}^{f i x}$. This condition is equivalent to

$$
\frac{k}{2 c}+\sqrt{\frac{\delta \bar{W}_{2}}{c}}>\frac{k+\delta \phi\left(\bar{W}_{2}-\bar{m}\right)}{2 c} .
$$

By using $\phi=\frac{1}{\bar{e}}$, condition (41) can be transformed into $4 c \bar{e}^{-2} \bar{W}_{2}>\delta\left(\bar{W}_{2}-\bar{m}\right)^{2}$. Using our assumption $\bar{e} \geq \frac{k}{2 c}+\sqrt{\frac{\delta \bar{W}_{2}}{c}}$, the condition becomes

$$
\frac{k^{2}}{\delta c} \bar{W}_{2}+4 \frac{k}{\delta} \sqrt{\frac{\delta \bar{W}_{2}}{c}} \bar{W}_{2}+2 \bar{W}_{2} \bar{m}+3 \bar{W}_{2}^{2}-\bar{m}^{2}>0,
$$

which is fulfilled since $\bar{W}_{2} \geq \bar{m}$.

Proof of Proposition 4 Part (i). The necessary condition for an equilibrium in the information market is that the number of investors with

$$
(1-q)\left[\bar{s}(1-p)\left(z \operatorname{Pr}_{j}\left(R E \mid \beta_{j}\right)+(1-z) p\right)-\bar{s} p\left(1-z \operatorname{Pr}_{j}\left(R E \mid \beta_{j}\right)-(1-z) p\right)\right]>0
$$

be equal to the number of investors with

$$
(1-q)\left[\bar{s}(1-p)\left(z \operatorname{Pr}_{j}\left(R E \mid \beta_{j}\right)+(1-z) p\right)-\bar{s} p\left(1-z \operatorname{Pr}_{j}\left(R E \mid \beta_{j}\right)-(1-z) p\right)\right]<0 .
$$

This condition will be fulfilled if the investor who obtains the median signal $\beta_{j}^{m}$ is indifferent as to buying assets $D$ or $E$ and thus if

$$
(1-q)\left[(1-p)\left(z \operatorname{Pr}_{j}\left(R E \mid \beta_{j}^{m}\right)+(1-z) p\right)-p\left(1-z \operatorname{Pr}_{j}\left(R E \mid \beta_{j}^{m}\right)-(1-z) p\right)\right]=0 .
$$


Inserting $\frac{\phi}{k} \beta_{j}^{m}$ for $\operatorname{Pr}_{j}\left(R E \mid \beta_{j}^{m}\right)$ and solving for $p^{*}$ yields equation (18).

Part (ii). The expected value for $\beta_{j}^{m}$ is equal to $E[\beta]$ as the signals $\beta_{j}$ are assumed to be distributed symmetrically around $E[\beta]$. Further, we know that $E[\beta]=b=k e$. Thus we obtain the expected value for the equilibrium price by inserting $k e$ for $\beta_{j}^{m}$ in equation (18). Moreover, we use $\frac{1}{\bar{e}}$ for $\phi$ and obtain equation (19).

Proof of Proposition 5 The incumbent has the following utility function:

$$
U_{N R}^{f l e x}=k e-c e^{2}+\delta m^{E}(e) .
$$

The first-order condition $\frac{\partial U_{N R}^{f l e x}}{\partial e}=k-2 c e+\delta \lambda=0$ implies $e_{N R}^{f l e x}=\frac{k+\delta \lambda}{2 c}$. According to our assumptions, $e_{N R}^{f l e x} \leq \bar{e}$, so the solution is feasible for the incumbent.

Proof of Proposition 6 The incumbent maximizes

$$
U_{R}^{f l e x}=k e-c e^{2}+\delta\left[r_{1}(e) \bar{W}_{2}+\left(1-r_{1}(e)\right) m^{E}(e)\right] .
$$

We insert $m^{0}+\lambda e$ for $m^{E}(e)$ and $\phi e$ for $r_{1}(e)$ and obtain the following first-order condition:

$$
\frac{\partial U_{R}^{f l e x}}{\partial e}=k-2 c e+\delta \phi\left(\bar{W}_{2}-m^{0}\right)+\delta \lambda-2 \delta \phi \lambda e=0 .
$$

Solving for $e$ yields $e_{R}^{f l e x}=\frac{k+\delta \lambda+\delta \phi\left(\bar{W}_{2}-m^{0}\right)}{2 c+2 \delta \phi \lambda}$. According to our assumptions, $e_{R}^{f l e x} \leq \bar{e}$, so the solution is feasible for the incumbent.

Proof of Proposition 8 For $m^{0}=0$ we obtain $e_{R}^{f l e x, m^{0}=0}=\frac{k+\delta \lambda+\delta \phi \bar{W}_{2}}{2 c+2 \delta \phi \lambda}$ when the incumbent runs for reelection. We prove $e_{R}^{f l e x, m^{0}=0} \geq e_{R R}^{f i x}$ by contradiction. Suppose $e_{R}^{f l e x, m^{0}=0}<e_{R}^{f i x}$, which implies

$$
\frac{k+\delta \lambda+\delta \phi \bar{W}_{2}}{2 c+2 \delta \phi \lambda}<\frac{k+\delta \phi\left(\bar{W}_{2}-\bar{m}\right)}{2 c} .
$$

By using $\lambda=\phi \bar{m}$, this condition can be simplified to

$$
\bar{W}_{2}>\bar{m}+\frac{2 c-k \phi}{\delta \phi^{2}} .
$$

By inserting $\bar{W}_{2}>\bar{m}+\frac{2 c-k \phi}{\delta \phi^{2}}$ into $e_{R}^{\text {flex, } m^{0}=0}$, we obtain

$$
e_{R}^{f l e x, m^{0}=0}=\frac{k+\delta \lambda+\delta \phi \bar{W}_{2}}{2 c+2 \delta \phi \lambda}>\frac{k+\delta \lambda+\delta \phi\left(\bar{m}+\frac{2 c-k \phi}{\delta \phi^{2}}\right)}{2 c+2 \delta \phi \lambda} .
$$

Furthermore, we can show that

$$
\frac{k+\delta \lambda+\delta \phi\left(\bar{m}+\frac{2 c-k \phi}{\delta \phi^{2}}\right)}{2 c+2 \delta \phi \lambda}=\frac{1}{\phi}=\bar{e} .
$$

Thus we have $e_{R}^{f l e x, m^{0}=0}>\bar{e}$ which is a contradiction as the effort choice under flexible pensions would be too large to be feasible. Hence $e_{R}^{f l e x, m^{0}=0} \geq e_{R}^{f i x}$. 
Proof of Proposition 9 For $m^{0}=\bar{m}$ we obtain $e_{R}^{\text {flex, } m^{0}=\bar{m}}=\frac{k+\delta \lambda+\delta \phi\left(\bar{W}_{2}-\bar{m}\right)}{2 c+2 \delta \phi \lambda}$ in the case where the incumbent runs for reelection. The level of effort under flexible pensions will be smaller than the level of effort under fixed pensions if $e_{R}^{f l e x, m^{0}=\bar{m}}<e_{R}^{f i x}$. This condition

$$
\frac{k+\delta \lambda+\delta \phi\left(\bar{W}_{2}-\bar{m}\right)}{2 c+2 \delta \phi \lambda}<\frac{k+\delta \phi\left(\bar{W}_{2}-\bar{m}\right)}{2 c}
$$

can be simplified to

$$
\bar{W}_{2}>\bar{m}+\frac{c-k \phi}{\delta \phi^{2}} .
$$

We next show that the effort under flexible pensions may be indeed lower than under fixed pensions. This is the case if the set of parameters $\left\{c, k, \delta, \bar{e}, \bar{m}, \bar{W}_{2}\right\}$ simultaneously fulfills condition (51) and the condition

$$
e_{R}^{f l e x, m^{0}=\bar{m}}=\frac{k+\delta \lambda+\delta \phi\left(\bar{W}_{2}-\bar{m}\right)}{2 c+2 \delta \phi \lambda} \leq \bar{e} .
$$

Let us choose

$$
\bar{W}_{2}=\bar{m}+\frac{c-k \phi}{\delta \phi^{2}}+\varepsilon
$$

for some $\varepsilon>0$. Then the second condition translates into

$$
\frac{k+\delta \phi\left(\bar{m}+\frac{c-k \phi}{\delta \phi^{2}}+\varepsilon-\bar{m}\right)+\delta \lambda}{2 c+2 \delta \phi \lambda} \leq \bar{e},
$$

which (by inserting $\frac{1}{\bar{e}}$ for $\phi$ and $\frac{\bar{m}}{\bar{e}}$ for $\lambda$ ) can be transformed into

$$
\frac{c}{\delta} \bar{e}^{2}+\bar{m} \geq \varepsilon
$$

Equation (55) will be fulfilled for small values of $\varepsilon$. Thus we have shown that the effort under flexible pensions may be lower than under fixed pensions.

Proof of Proposition 10 We calculate $m^{\text {crit }}$ such that $e_{R}^{f l e x}=e_{R}^{f i x}$. This condition

$$
\frac{k+\delta \lambda+\delta \phi\left(\bar{W}_{2}-m^{0}\right)}{2 c+2 \delta \phi \lambda}=\frac{k+\delta \phi\left(\bar{W}_{2}-\bar{m}\right)}{2 c}
$$

can be simplified to

$$
m^{0}=\bar{m}-\frac{k \lambda+\delta \phi \lambda\left(\bar{W}_{2}-\bar{m}\right)}{c}+\frac{\lambda}{\phi} .
$$

By inserting $\bar{m}$ for $\frac{\lambda}{\phi}$, we obtain the critical value $m^{\text {crit }}$. It is obvious that $m^{\text {crit }}>0$, as we have shown in Proposition 8 that for $m^{0}=0$ flexible pensions are always weakly welfareincreasing. 


\section{Appendix B: Corner solutions}

In this Appendix we prove that our assumption

$$
\bar{e} \geq \frac{k}{2 c}+\sqrt{\frac{\delta \bar{W}_{2}}{c}}=e_{R}^{f i x, F B}
$$

is sufficient to ensure interior solutions in all cases by showing that under this assumption all interior solutions are smaller than the physical constraint $\bar{e}$.

The highest possible effort choices with interior solutions are given by

- Fixed pensions: $e_{R}^{f i x, F B}=\frac{k}{2 c}+\sqrt{\frac{\delta \bar{W}_{2}}{c}}$.

- Flexible pensions with $m^{0}=0: e_{R}^{f l e x, m^{0}=0}=\frac{k+\delta \lambda+\delta \phi \bar{W}_{2}}{2 c+2 \delta \phi \lambda}$.

As our assumption is equivalent to $\bar{e} \geq e_{R}^{f i x, F B}$, it remains to be shown that $\bar{e} \geq e_{R}^{f i x, F B}$ implies $\bar{e} \geq e_{R}^{f l e x, m^{0}=0}$. By using $\phi=\frac{1}{\bar{e}}$ and $\lambda=\frac{\bar{m}}{\bar{e}}$, the condition $\bar{e} \geq e_{R}^{f l e x, m^{0}=0}$ can be transformed into

$$
\bar{e} \geq \frac{k+\sqrt{k^{2}+8 c \delta\left(\bar{W}_{2}-\bar{m}\right)}}{4 c} .
$$

It is straightforward to verify that $\frac{k}{2 c}+\sqrt{\frac{\delta \bar{W}_{2}}{c}}$ is larger than $\frac{k+\sqrt{k^{2}+8 c \delta\left(\bar{W}_{2}-\bar{m}\right)}}{4 c}$. Thus $\bar{e} \geq$ $\frac{k}{2 c}+\sqrt{\frac{\delta \bar{W}_{2}}{c}}$ implies $\bar{e} \geq \frac{k+\sqrt{k^{2}+8 c \delta\left(\bar{W}_{2}-\bar{m}\right)}}{4 c}$, which proves our claim.

\section{References}

Alesina, A., \& Spear, S. (1988). An overlapping generations model of electoral competition. Journal of Public Economics, 37, 359-379.

Baker, G. (1992). Incentive contracts and performance measurement. Journal of Political Economy, 100, 598-614.

Barro, R. (1973). The control of politicians: An economic model. Public Choice, 14, 19-42.

Becker, G., \& Stigler, G. (1974). Law enforcement, malfeasance and the compensation of enforcers. Journal of Legal Studies, 1, 1-18.

Bender, B., \& Lott, J. (1996). Legislator voting and shirking: A critical review of the literature. Public Choice, $87,67-100$.

Berg, J., Forsythe, R., \& Rietz, T. (1996). What makes markets predict well? Evidence from the Iowa electronic markets. In Understanding strategic interaction: Essays in honor of Reinhard Selten. Berlin: Springer.

Berlemann, M., \& Schmidt, C. (2001). Predictive accuracy of political stock markets. Empirical evidence from a European perspective. Discussion Paper, Humboldt-University of Berlin.

Carey, J. (1994). Political shirking and the last term problem: Evidence for a party-administered pension system. Public Choice, 81, 1-22.

Fair, R. (1996). Econometrics and presidential elections. Journal of Economic Perspectives, 10(3), 89-102.

Gersbach, H. (2003). Incentive contracts and elections for politicians and the down-up problem. In M. Sertel \& S. Koray (Eds.), Advances in economic design. Berlin: Springer.

Gersbach, H. (2004). Competition of politicians for incentive contracts and elections. Public Choice, 121, 157-177.

Gersbach, H., \& Liessem, V. (2008). Reelection threshold contracts in politics. Social Choice and Welfare, $31(2), 233-255$.

Gersbach, H., \& Müller, M. (2006). Markets, contracts, and elections. CER-ETH Discussion Paper, ETH Zurich, 06-56.

Gibbons, R. (1998). Incentives in organizations. Journal of Economic Perspectives, 12, 115-132.

Grossman, S., \& Hart, O. (1983). An analysis of the principal-agent problem. Econometrica, 51, 7-45. 
Hahn, R., \& Tetlock, P. (2004). Using information markets to improve policy. AEI-Brookings Joint Center Working Paper, 04-18.

Hanson, R. (2003). Shall we vote on values, but bet on beliefs. Mimeo, George Mason University.

Hibbs, D. (2000). Bread and peace voting in US presidential elections. Public Choice, 104, 149-180.

Holmström, B. (1979). Moral hazard and observability. Bell Journal of Economics, 10, 74-91.

Lazear, E. (2000). Performance pay and productivity. American Economic Review, 90, 1346-1361.

Millimet, D., Sturm, D., \& List, J. (2004). The economic consequences of electoral accountability revisited. Mimeo, University of Munich.

Mirrlees, J. (1976). The optimal structure of incentives and authority within an organization. Bell Journal of Economics, 7, 105-131.

Morris, P. (1983). An axiomatic approach to expert resolution. Management Science, 29(1), 24-32.

Rosenblueth, E., \& Ordaz, M. (1992). Combination of expert opinions. Journal of Scientific and Industrial Research, 51, 572-580.

Smart, M., \& Sturm, D. (2004). Term limits and electoral accountability. CEPR Discussion Paper, 4272.

Wolfers, J., \& Zitzewitz, E. (2004). Prediction markets. Journal of Economic Perspectives, 18(2), 107-126.

Wolfers, J., \& Zitzewitz, E. (2006). Five open questions about prediction markets. Federal Reserve Bank of San Francisco-Working Paper Series, 2006-06. 